\title{
THE SYSTEM OF THE ENGLISH CHEMICAL SOCIETY.
}

The system of nomenclature and notation adopted by the English Chemical Society, which has already been referred to, is here reprinted in full.

\section{Nomexclature and Notation.}

The following instructions relating to these matters were add lessed by the Council to the Abstractors in 1879*, and are now reprinted, with a few slight alterations, in the hope that they may have some influence in promoting uniformity of nomenclature and notation, especially in papers communicated to this journal.

By order of the Publication Committee,

H. WATTS, Editor.

\section{NOMENCLATURE.}

"1. Employ names such as sodium, chloride, potassium, sulphate, etlyyl acetate, and use the terminals ous and ic only in distinguishing compounds of different orders derived from the same elementary radicles, e. g., mercurous and mercuric chloride, sulphurous and sulphuric acid.

"2. Term compounds of metallic and alcohol radicles with $(\mathrm{OH})$, hydroxides and not hydrates, e. $g$., potassium hydroxide, phenyl hydroxide, the name hydrate being reserved for compounds supposed to contain water of combination or crystallization. Compounds such as $\mathrm{CH}_{3} \mathrm{ONa}, \mathrm{C}_{2} \mathrm{H}_{5} \mathrm{ONa}, \mathrm{C}_{7} \mathrm{H}_{15} \mathrm{ONa}$, etc., should be termed sodium methoxide, ethoxide, heptyoxide, \&c.

"3. Apply the term acid only to compounds of hydrogen with negative radicles, such as $\mathrm{HNO}_{3}, \mathrm{H}_{2} \mathrm{SO}_{4}, \mathrm{H}_{3} \mathrm{PO}_{4}$, and denote the oxides which form acids by names such as sulphuric anhydride or sulphur trioxide. Term salts containing an amount of metal equivalent to the displaceable hydrogen of the acid, normal and not neutral salts, and assign names, such as hydrogen-sodium sulphate, hydrogen-disodium phosphate, \&c., to the acid salts. Basic salts are as a rule best designated merely by their formulce.

"4. Use names such as methane, ethane, \&c., for the normal paraffins or hydrocarbons of $\mathrm{C}_{n} \mathrm{H}_{2 \mathrm{n}+\mathrm{z}}$ series of the form $\mathrm{CH}_{3}$. 